\title{
Restructuring of Banking: Concept, Justifications, Stages and Results
}

\section{Laounia Benzekkoura}

Assistante professor at the University of Mascara

Lakhdar Adouka

Lecturer at the University of Mascara

Abderrahmane Chenini

Lecturer at the University of Mascara

Doi:10.5901/mjss.2014.v5n4p123

\begin{abstract}
Banks play an important role in the economic system, this fact of their responsibility for all deposits, on the one hand and managing means of payment other. They constitute one of the pillars of power and an aspect of economic competition globally. The bank was considered an administrative institution who enjoyed the protection of the public authorities, the performance parameter did not matter. A party of twenty-four years, the activity of banks experiencing financial liberalism and are subject to new regulations and banking laws. The essential goal is to reduce the influence of the central authority on the financial system to minimize the role of the monetary authority. This allowed the financial and banking system to develop in the light of changes in financial and banking variables and increasing competition. In this atmosphere and to track changes and to face the challenges from globalization and increased competition from banks and non- financial institutions, banks were essential to restructure their operations to position itself in the banking and financial markets. In this article we try to spread out the restructuring, its definitions, its mandatory and different methods of bank restructuring and the issues and the consequences resulting there from.
\end{abstract}

Keywords: Banking, financial system restructuring, financial crisis.

\section{Introduction}

Banks represent an important pillar in the economic system they are working to collect deposits from Hah and the granting of credit on the other. Known banking activity in the years of the eighties significant shifts due originally to edits banking and reorganization legislation and regulation of banking in order to weaken the central authority on the financial system and reduce the role of the monetary authority in the organization, and from here began to financial and banking system to evolve and adapt to the financial variables new bank with taking into account the role of the growing competition in this ocean .

In order to keep pace with the banks of the developments of financial and banking, as well as meet the challenges of globalization of banking and intense competition by banks and non-financial institutions, it was incumbent on the banks restructure its operations and practices to ensure a place in the banking market, financial, and therefore problematic search centered on :

How to contribute restructuring strategy has recast the banks?

Based on this problem can ask questions of the following sub:

- What is restructuring ?

- What are the stages of restructuring?

- What is the justification?

- What types of restructuring?

- What the consequences of restructuring?

The importance of research : the importance of the subject centered in the show.

- The role of the restructuring process in building strategy has banking institution in accordance with the 
changes and developments in the financial arena.

- Identify strategies for restructuring, both from the inner side or outer side of.

- Identify the most important ways available to the banking institution in the light of the financial variables arena.

Find divisions : Based on elements of the study can be divided into :

1. what the restructuring and conditions for their realization

2. stages of restructuring

3. the justification for bank restructuring

4. Types of bank restructuring

5. methods resulting from the restructuring of bank

6. Results of bank restructuring

\section{The Concept of Restructuring and Conditions for their Realization}

The banking system sectors active in economic management, he is working on the mobilization of savings in order to direct them to invest, on this basis, banks have to cope with the new conditions in the ocean the financial and banking by applying the policy to restructure the banking industry .

If the intended restructuring of banking? What are the conditions to achieve? And stages ?

\subsection{The definition of restructuring}

The process of restructuring the banking of great importance for the banks on the grounds that they allow the formulation of the new strategy and the future to meet the challenges of financial globalization, and on this basis we will try to address the various concepts of restructuring both in the general framework or at the level of the banks.

A. General concepts: express term restructuring Restructuration in French or English Re-structing raise the efficiency or re-construction or design on scientific grounds. We have numerous concepts related to restructuring and the different views of researchers, among them (1):

- restructuring focuses on an important shift in the levels of middle management, and the rebuilding of the work processes, leading to reduced parts of the process and it is through the delegation of authority for employees and the use of information technology in emergency communications and information transmitted rapidly.

- restructuring is one of the more radical solutions in a comprehensive and in-depth changes, and may include a shift from a functional organization to other grounds specified by the facility.

- Richard, Herring: include restructuring the closure of failing institutions ( bankrupt ) and develop a framework for the liquidation of the debt or merged to form a vital entities. May accompany this process of political and constitutional reforms to varying degrees in order to enhance the efficiency of the financial system for the future. Through this concept can be said that the restructuring process focused on the development of solutions to the problems in the financial institution failed, Either liquidated or merged with other institutions.

- while Kotler believes that the restructuring are reshaping the work of the organization in order to bring about radical changes in the business environment, for example : a readjustment of information technology and telecommunications, and to respond to major businesses come through the successive changes in the environment.

On this basis, can formulate a comprehensive definition of restructuring includes a change in the method of working through the structure of responsibility and communication channels and facilitate action by the use of technology in the application of new ideas and styles.

B. The concept of restructuring the bank: The definition of restructuring expenses varies depending on the opinions and researchers in this field, there are those who see it (2):

- (Claudia \& Ceyla) restructuring of the bank means to improve the performance of the bank during the restore solvency and financial mediation .

- The restructuring is to encourage mergers between banks and especially among small banks in order to create a large banking can provide a variety of banking services, integrated and competitive cost .

- reflect the process of restructuring the bank for the failure of individual banks to do morphological which calls for the use of regulatory programs and any corrective comprehensive restructuring of the bank. 
- represent the process of restructuring the bank's comprehensive and systematic way using the tools are:

- liquidation of the debt owed

- Re capital into banks

- operational restructuring ( the process)

- not working process of restructuring the banking sector and financial forcing financial institutions failed ( improper ) to leave the market, in order to solve the problem of bad debts. It can be said that the restructuring of the banks is a comprehensive plan to discuss the current situation of the bank and to develop a new strategy for his work in a competitive environment, taking into account the cost of it.

\subsection{Terms of the success of the restructuring process}

for the success of the restructuring process in an organization, you must rely on the basic conditions of the following (3) :

- mandatory presence of a strategic plan that includes a clear policy framework for the organization and the media (internal and external ) ,

- selection method and techniques attached to him, as well as the distribution of incoming human and material resources to the restructuring process.

- Subscribe serial real, especially direct sequencing of the workers in the composition and the achievement of results in response to the strategic planner.

- Effective leadership of the information system and the focus of negotiations and meetings with partners .

- Activating the institution of measures to allow a change of structuring human material.

- Assessment and management of the economic cost of the restructuring process in a way that allows avoiding the waste of resources or damaging to the institution.

And on this basis can the process of restructuring to pass after the phases and help at the same time contribute to the selection and organization of the means ( human and material ) to activate this process .

\section{Stages of Restructuring}

Depends restructuring process on three basic stages, centered on how to build a strategic plan to see the situation the future and how to access them and then planned social studies the structure of the giant human classification and hence know the means available to rebuild the institution replace the restructuring , according to the following structure (4)

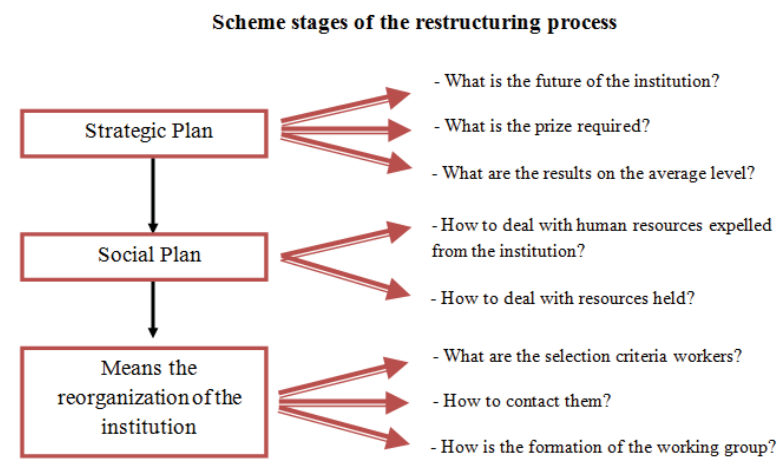

- The preparation of the strategic plan : build a strategic plan allows the identification of a range of themes based on asking questions in depth is interested in knowing the future status of the institution by determining the price of restructuring and thus know the results in the medium term. The process of restructuring as a real strategy through:

- bonding based on the analysis of the real the real requirements of the institution.

- mobilization and participation of all stakeholders within the organization process.

- translation of specific objectives based on the means of implementation through the development calendar for it. 
- Knowledge of the structure of workers by determining the effects and the cost of rehabilitation or transferred or abandoned.

Through the above it can be said that the construction of the strategic plan in order to be (5):

- give a true and credible in the future of the institution (see results in the medium term, forecasts future price too).

- $\quad$ persuade and mobilize workers who will participate in the future stage.

- ensuring coherence in the decisions and debates during the restructuring period.

- Facilitate consultation with various stakeholders (officials - representatives of workers and trade unions, management and the local environment ......).

- Allow describe and identify the institution replace restructuring in order to learn the necessary corrections to it.

- Preparation of the planned social : The social part of the planned strategic plan and the aim is to achieve the greatest results of the restructuring process, and therefore, this scheme includes standards conditioning workers held their hand, and standards of workers' compensation abandoned on the other hand . To achieve the planned social must rely on the following:

- analysis of the determinants that allow the achievement of planned and comes to know the characteristics of the institution, its surroundings, the results of adjustment, the time required, the resources available .... etc. .

- Choose determinants of the most adaptable to the status of the institution.

This is achieved through planned social consultation and consensus among officials of the institution and the workers as well as their representatives in order to reach appropriate solutions to save the organization and problem-solving.

- Means reorganization of the institution : The work on the reorganization of the institution in order to face competition within the market, through good analysis of the predicament which allows draw a future plan to continue the activity and it must identify:

- The main characteristics of the institution, both with regard to any size, sector of activity, the culture of the institution in the field of human resources management, the degree of independence, major shareholders strategy .... etc. .

- study of the causes and the importance of the size of the workers (either increase or even in the case of abandonment) illustrate the impact of any workers on the activity of the institution.

- Identify the time needed to address the problems according to calendar time.

- Knowledge of the status of the institution in its surroundings (locally, regionally, nationally).

- Study the properties of the layer of staff involved in the restructuring of the hand (age, sex, level of education and qualification level)

- The estimated budget for it, and the means available to complete the restructuring process.

Through three stages conclude that the activation of the restructuring process at the level of any institution must achieve a strategic plan depends on the conduct of the surplus in the human material out of the selection of appropriate standards for the separation of human resources capable of developing enterprise and the resources that represent a burden on the planned development of the institution. The process of restructuring strategy for the performance of the institution in order to keep up with developments in their surroundings.

\section{Justification for Restructuring}

The restructuring of the banking and applicable way to make radical changes at the level of the bank's strategy in order to improve performance and improve the services provided to customers and thus re- positioning in the banking and financial market, and most important of these justifications are:

\subsection{Reorganization}

I knew most of the banking systems beginning years of the eighties the reorganization of its activities through the reform legislation and regulations, the bank took a reorganization two basic forms that contained liberalization of the traditional functions of banks and adopt a policy of diversification and the development of new functions, as summarized 
reorganization size of banks as well as the pricing policy (rates of bank interest rates), which allowed access to the globalization of the jobs bank with the help of the process of removing geographical barriers in front of the banking and financial transactions (6).

\subsection{Increasing competition}

under the Banking and Financial transformations intensified competition in the banking industry, both among banks among themselves or between banks and non-financial institutions, prompting the authorities concerned to find the necessary solutions to meet these challenges. The strategy of the banks at this stage to follow the focus of several policies such as the banking, diversification in functions or policies to expand through mergers and acquisitions. Appeared competitive process through financial liberalization and banking and reorganization legislation and regulations relating to the banking business in addition to the deletion of barriers to capital movements, all these factors contributed to the increased competition in the banking industry.

\subsection{Banking crises}

led financial globalization in the nineties to the emergence of a wave of accelerated liberalization of the financial and banking sector, which contributed to the occurrence of financial crises have often been accompanied by changes of a strong exchange rate of the currency in the country replaced the crisis. Known as the banking crisis as a sudden increase and large in the process of withdrawal of deposits, compared to operating intensive these deposits by the bank in the form of loans (7).

Has been confirmed by a study of 53 countries in the period between 1980-1995 (8) the relationship between financial liberalization and financial fragility , as the rising incidence of banking crises was due to the policy of financial liberalization pursued by these countries. Appear banking crisis when confronted with a bank and a sudden large increase to request the withdrawal of deposits and can not meet because of the lack of liquidity necessary, and what is happening here is called a liquidity crisis at the bank, if the spread of this problem to other banks this case is called a banking crisis .

In light of financial liberalization and banking operations, has become more prevalent morphological crises due to infection by the mobile open financial markets, banking and the globalization of banking activities. Among the most important contributing factors in the incidence of banking crises is intense competition between banks and other financial institutions in the area of speculation in the financial markets and dealing in derivatives, which led to instability in the general economy as a result of dealing with capital and short-term expansion in operations outside the budget.

\subsection{Technology developments}

Affected banking activities and financial and technological transformations, especially the tremendous development in the field of information and communication and the Internet, has allowed these developments to devise new ways to get closer to customers.

Of the most important demonstration of progress in the provision of banking services is expanding the use of the computer where this led to the speed in the delivery of services and reduce the bureaucratic burden and save time for both customers and bank employees, also contributed to developments in technology, particularly the Internet to keep up with the volume of financial transactions increased, especially after the financial openness markets, and attic access client services required in any branch of the bank in question.

As well as advances in banking technology is the use of modern technologies, such as the use of electronic means of payment of various kinds ( plastic money, credit cards, smart money, electronic money...) and the increasing volume of electronic banking transactions across the border by the so-called electronic commerce, in addition to free customers from the constraints of time and space and the emergence of what is known as home banking or phone. Based on these developments, I tried all the banks to keep pace with technological advances to meet the challenges of the global financial by creating legal ground and legislative to facilitate the application of information and communication technology in banking operations, as well as the diversification of banking services and the development of banking marketing, depending on the rehabilitation of the human race to keep up with developments in the banking business (9). 


\section{Types of Restructuring}

The restructuring process took two forms are important in order to allow the organization to cope with the developments of the surroundings; it comes to the internal restructuring (method of internal growth) and restructuring of State (method of external growth).

\section{1 internal restructuring}

The process of internal restructuring allows the selection of a strategic reorganization of the structure of the institution in accordance with the standards and specific forms.

A. Standards applied internal restructuring: allow internal restructuring and the development of production units by creating new production capacities (10). It comes to model the development of sustained capacity within the organization or the creation of productive capacity and new business either by using new technologies or open branches for sale and distribution, and here Foundation is working on the development of qualifications (work item , component of the raw material needed in the production process, as well as an element of capital) and so without prejudice to the legal personality (the institution remains the province of the financial and economic independence ).

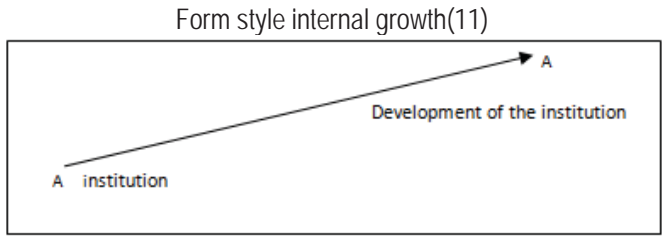

This is accomplished first model, through the development of forecasts of future short-term, medium and long term for the state of the institution and takes to the full mobilization of the financial resources available and which can be obtained in order to achieve the strategic plan must also restructure the human system (human resources) within the institution by Ranked to human resources needed to follow up the progress of the institution and the other a burden

Forms of achieving internal growth : the institution can use two forms of internal growth to achieve the objectives of the ruler, a growth by production units to new assets with a view to expansion ., Or through the purchase of new units to be integrated in the institution as the institution can you rent or sale leasing (Leasing) in order to get additional assets contribute to the growth and development of the institution.

What can be seen through the forms of internal growth is the practice of the institution to operate under the management style development without compromising the legal personality and relying on :

- focus their resources in existing markets by products are able to do so.

- begin to produce new products in the markets be present where any search for new market share.

- start in new markets within the new markets ( diversification policy).

B. Motivated approach internal growth : the institution to follow the model of internal growth in the following cases

(12)

- when high demand or in the case of geographic expansion .

- When the evolution of production techniques and style of consumption is significant.

- when prices change associated with the elements of production .

- When can achieve economies of scale through the growth of production capacities in the organization.

\subsection{Restructuring of State}

represents the process of restructuring a foreign methods used by the organization in order to improve their performance and meet the competitive environment in which it operates, this process is based on the method of buying property in another institution for the formation of a new structure either convergence or integration of functions in the institution another institution. 
Form of external growth

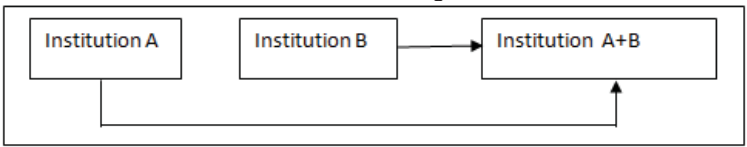

Growth model is achieved through the outer union of two or more to show a new entity capable of achieving the objectives of the ruler of the hand and face the challenges of competition on the other. According to the above definition, can be drawn from the two forms of the restructuring of State, namely:

Figure I: Limited expansion and includes all changes and transfers ownership of the assets of an enterprise through mergers and acquisitions or through a waiver of asset operations , called often "operations focus".

Figure II: Expansion includes comprehensive surveillance operations within the credit system between the various units ( branches simple , common branches ... etc.), all forms that help monitor the development of the assets.

The reality of the process of restructuring the external world : I knew the process of restructuring the external remarkable development beginning years of the eighties and until the nineties a strong push in the area of external growth in all sectors, without exception, in the area of finance and banking have contributed to economic and financial conditions, which were the result of repeated crises in Find new ways to develop the banking industry . can be divided into periods of growth outside the so-called re- structuring bank to the following stages:

- the stage of the eighties : included operations expanding in the field of restructuring the bank through a policy of reform banking on the one hand, the reform legislation and banking laws on the other hand, and it took a practical method of growth of the institution outside but dye and a national sense that the merger has been in the national framework.

- the stage of the nineties : is the stage of development of the enormous growth of the outer cross-border, and have known this period many of the mergers between banking institutions in Europe and even in the USA. M. A.

- the current stage : can be divided this stage into three stations, which represent the period between 19972000 flowering stage of restructuring of banking and therefore the acceleration of mergers and acquisitions as a result of corrections ongoing legislation bank, in the period between 2003-2007 (13), the percentage of mergers in the banking and financial sector to $53 \%$, while they knew the decline in the period between 2007 to 2009 by $32 \%$ due to the repercussions of the economic and financial crisis , but at the moment it has formed a new renaissance of these operations in the fourth triple of the year 2011 to reach $50 \%$

The evolution of restructuring across the world (14)

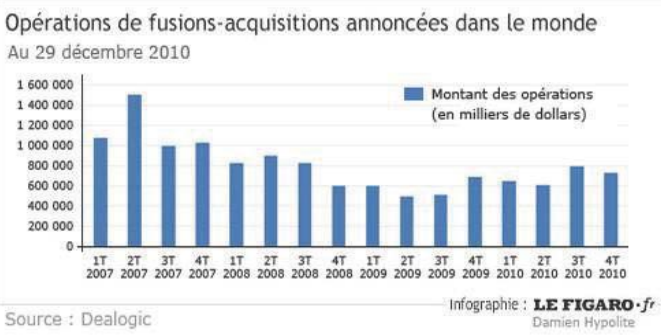

External growth strategy included a remarkable development in the field of banking and finance in Europe as in the United States, either through the national integration of banking and financial institutions, or through any external integration of cross-border or the convergence of banking and financial jobs.

\section{Methods Resulting from the Restructuring}

The process of restructuring of the banking industry through mergers and acquisitions in the field of financial and banking services include several types, as the transactions are made between different types of banking institutions ( domestic and foreign ) financial institutions ( domestic and foreign ) as well as non-financial institutions such as insurance companies ( domestic and foreign ) for the different methods of restructuring institutions in different styles and objectives. 
- Formation of banking groups: under the influence of growing competition, banks embarked on a strategy to focus the bank through the formation of banking group is able to address the challenges posed by financial globalization.

Does not consider the phenomenon of modern banking focus origin In the period between 1960-1970 (15) blocks formed with the aim of diversifying the jobs in the years of the eighties was a race to possess the largest market share through mergers $\mathrm{F} \& \mathrm{~A}$ while in the nineties was a trend towards the globalization of banking activities by adopting comprehensive model Bank, and currently remains oriented towards the formation of the banking and financial banking groups on a global level.

The recent trend towards the formation of the giants in the field of banking industry, was based on various financial transformations especially financial liberalization and the deletion of various barriers to the movement of capital , as well as reorganization of the various legislation and banking laws.

Through restructuring processes managed these groups banking password from strategy to internationalize its functions to the strategy of the globalization of its banking. Contribute to the globalization of banking operations in the formation of the giants of the banking industry through the opening of bank branches across various countries around the world and thus expand its activities and operations within and outside the country.

- Creation of new institutions and the development of the partnership: depends principle do or create new institutions on one of the main elements of the shifts of financial and banking arising from financial globalization , a deletion of geographical barriers in front of the banking and financial Despite the attempt of local banks for any country to meet the challenges of financial globalization , but the intensity of competition banking pay banks to find solutions through :

- Restructuring of its activities through the introduction of new functions.

- Partnership between the various banks or between banks and non-financial institutions in order to create a new entity.

- Open branches on a global level for the giant banking groups by opening up the financial and banking.

- Aimed at the process of creating new institutions and the development of the partnership between financial institutions and the banking market to the formation of a global bank. Supports the principle of the creation of institutions and development partnership to open the banks' capital contributions to local and foreign various types of contributions, whether individuals or institutions.

- Institutional renewal: the evolution of the competition helped the emergence of new products and processes as payment Ocean change the financial and economic institutions, banking and finance to adapt the structure and pattern of conduct even fit in with the requirements of the new environment through :- The constant search for the continued growth of the institution by market share related to the size of the institution.

- Create value based on the dominant position in the market on the one hand and to reduce costs and increase economies of peace on the other hand.

- Focus on the renewal and diversification of services proposed to customers.

- The development of management systems in line with the market variables using the most advanced technology in the field of information and communication Reliance on methods of caution in the conduct of the banks portfolio (respect for the decisions of the Basel Committee).

- Variety of jobs : contribute to the process of restructuring in the banking banks to adopt several strategies to meet the challenges of growing competition was the recent opening of bank branches in either locally or externally as a result of financial liberalization and banking and delete geographical barriers in front of the banking business.

As a result of these changes the financial and banking managed financial systems and banking for many countries to expand by opening bank branches throughout the world, for example, in France, the number of credit institutions through the world's 944 Foundation French in 2005 while received financial and banking system the French 237 Foundation loan in 2006 (16).

Process aims to open bank branches in response to the banking institution to the variables surrounding the financial and banking sector and increased competition in the market by working on the diversification of the services required by the customers depending on the cutting-edge technology includes the diversification of functions:

- Retail Bank

- Bank finance and investment (brokerage firms, investment companies) 
- Specialized financial services (leasing companies loans and rent -Credit bail et location), insurance services.

- Function the conduct of assets

This diversification has helped in the jobs bank branches to participate in many of the financial functions across the world.

\section{Results Restructuring}

contributed to the restructuring in the development of the banking industry dramatically since allowed the entry of banks into the fields and the fields were not operate before, as well as to strengthen and enhance the status of banks by following a variety of strategies to maintain its position in the banking market, both local and global levels.

\subsection{Goals restructuring}

popping the restructuring process as a result of shifts of the global financial particular delete geographical barriers in front of the banking business and the resulting reorganization legislation and banking laws in line with, in addition to financial liberalization and banking sector and the subsequent adoption of various policies to maintain the status of banks and promotion, on this basis can clarify the objectives of the restructuring are as follows:

- Strategic objectives: to achieve the strategic goals of the restructuring process whether we are in the process of development of the institution or the creation of new entities through (17):

- Increase the bank's ability to face competition locally or globally: through the face of the challenges of financial globalization of financial liberalization delete the centrality of geographical barriers on the movement of capital and reorganization.

- Improve banking performance : through the development and diversification in the provision of financial and banking services, based expertise and the use of advanced technology .

- Expanding the scope of the banking business : follow the policy of diversification of products and services offered to customers .

- Draw a strategic plan : to see the human resources necessary to continue the banking business, as well as the resources that represent a burden on the bank, and therefore the possibility of taking the necessary decision on layoffs, as well as the rest of the development of human resources.

- Broaden the base of contributors: to raise the volume of business through diversification of portfolio investments as a result of pooling of resources of the largest and therefore the potential risks.

- Economic goals: help the restructuring process to achieve the economic goals through (18):

- Provide funding for economic activity : by expanding the shareholder base and thus diversify the portfolio of investments that will allow the financing of the public sector, private or small and medium enterprises .

- Work on the development of the financial market : the restructuring process will allow the development of the banking business, which in turn allows the revitalization of the work of the financial market by providing the funding necessary to deal in securities and derivatives

- Contribute to support investment and the creation of projects : by providing the necessary funding for various economic agents in different formats and in accordance with the standards and criteria required .

- Work on the development of the productive sectors: providing financial products and services necessary and required quality in light of the global financial shifts.

Goals, especially in the banking sector : The aim of the process of restructuring the banking primarily to.

- Address the situation of the banks: and it comes to a comprehensive study of the situation of financial and structural Bank, especially the troubled banks.

- Create a strong banking entities : following the structural adjustment of the banking institutions diseased ( defaulted) through melting under other institutions characterized more effectively or try to configure the entities huge by mergers, whether it is related to mergers local or cross-border be able to develop the banking industry by improve productivity and reduce costs.

- Stimulate the banks to face the global financial developments by increasing the competitiveness of their approaches through research and development in the field of services provided to customers in terms of quality and speed depending on the technological developments in the field of banking industry.

- Opening the way for banks to diversify its shareholder base and depositors: and thus provide the 
necessary resources to meet the needs of the Bank.

- The possibility of expanding the activity of banks : to include the fields and different areas such as insurance or investment and other areas, in response to customer requirements, as well as the financial requirements of the transitions arising from financial globalization.

- The possibility of reducing the risk: Using modern management and advanced, as well as respect for international standards for monitoring prescribed by the Basel Committee.

\subsection{Benefits of the restructuring process}

Led fluctuations and shifts the financial and banking world has seen to increase competition between banks locally and globally, prompting banks to look for solutions to face it, where abused it the possibility of the development of the institution for their financial capabilities and human resources to reach the degree of formation of banking institutions new.

Technology has helped the revolution in communications and information banking entities in the face of the new challenges of global competition by modernizing management systems and applying advanced technologies in runs (enter computer systems and the Internet, electronic banking ... etc) .We have imposed financial and banking transformations follow modernization and development of banking laws and regulations in accordance with the principles of financial globalization thus providing the possibility of working cross-border banking, and the benefits can be summarized in the restructuring process are as follows:

- The possibility of improvement due Friendly Bank by controlling the costs of operations - Diversification of products and services and developed to expand the customer base and thus increase the reputation of the bank.

- The use of advanced technology in banking operations (Bank -mail and various payment methods talk)

- Increase the competitiveness of the bank by the quality of services and products offered to customers

- Minimizing the risk as a result of respect for safety standards prescribed in the agreements Pal

- The expansion of the bank's resources by increasing the shareholder base and open branches across the world

- The possibility of building or creating a bank entity is able to meet the challenges of the global financial shifts.

\subsection{The challenges resulting from the restructuring}

The restructuring process for the reorganization of the structures of the institution with a view to correcting the vessels to reach the objectives of the ruler within a future strategy that takes into account the changes in markets and technology . Despite the fact that the restructuring process is a representation of the organization's need to change the overall strategy in order to keep up with the changes of financial and banking but there are a range of challenges resulting from this process is to (19):

- External growth or partnership: can express term partnership when there are a variety of means to achieve specific goals and thus the possibility of the conduct of these means by controlling the various expenses especially the expenses of workers in the vicinity of the challenge, both for the institution of banking or other financial institutions (it comes in the conduct of available capital by controlling the operational expenses at the same time). Experience has shown in many countries, the fragility of the partnership where This stage is just the process of transition to the stage of restructuring and building strategic enterprise For example, the end of the partnership between the National Bank of Paris BNP and Bank Liga BBV (BBVA currently) and the end of the relationship between BNP and Deutsche Bank, Dresdner in some countries in the Middle Based on this can be considered a partnership a form of turning to either the merger or termination and interruption of cooperation between the two institutions and thus can be explained by the failure of the partnership bank through different strategy applicable to each partner, the objectives set, as well as the techniques used ... etc. and it can not be solved Partnership replace growth processes exterior which is made by mergers and acquisitions.

- Success or failure of the restructuring: can be divided into the success or failure of the restructuring in the long term and not in the short term, based on the results of mergers and acquisitions between institutions and to find out how effective the organization must build on a set of elements (quality management Business Management, circulation of information, structural organization etc ... ). This can result in bank mergers in the short-term decrease in the effectiveness of the new entity due to several factors such as different institutions 
merged, as well as trying to conduct pre-existing problems, whether from his managers on the one hand or laid-off workers .

- Banking focus and intensity of competition : focus creates the authority of the banking market in favor of big dealers Is this represents a threat for customers ? (20), to determine the effect of focusing the banking unit of competition on the behavior of customers, should distinguish between two types of customers, wholesale customers and retail customers, for organizations large multinational It deals with wholesale customers and therefore focus the bank does not affect the intensity of competition is not to choose between funding through mediation or funding in the market. While the problem remains at the level of retail customers ( individuals and small enterprises ), where the focus creates a conflict between bank problematic banking institutions through the competition in order to provide the products and the quality of banking services to customers.

- Financial crisis and speed up restructuring : the financial crisis has led to a weakening of some of the banks, which contributed to the emergence of the contrast between successful organizations and institutions on the one hand, on the other failed and thus accelerate the reorganization (21).

- For the banking and financial industry and the race for the size, which explains mergers and acquisitions in the banking sector accelerated since fiscal 2008.

- The fragility of the banking system : contributed to the restructuring process in correcting the failure of some banks through the processes of convergence that has been in the banking sector and of mergers and acquisitions and thereby forming entities banking giant. Based on this can be asked the following question: Is the focus banking reason for the fragility of the system banking?

- In the beginning, the focus bank as a result of the fragility of individual banking institutions, but the current studies proved the contrary based on the principle of TBTF «too big to fail» where banking institutions with large volume resulting from operations focus bank exposure to failure or loss because of the dangers of regular (risques systémiques) affect the degree of confidence and growth. The danger of banking groups large in increased confidence in the repositioning of the financial and thus the possibility of decline in the quality of the pledges have (loans, bonds acquired or purchased) as a result of reliance on central bank intervention to save the situation in the event of failure considering that these groups impact on the monetary policy of the country. On this basis, the central banks must take the principles of caution and care in monitoring this type of institutions.

- Legal challenges resulting from the restructuring allowed: the restructuring of the bank to adopt several criteria to monitor the results arising there from so as to avoid negative repercussions in the banking industry. Revolved these standards in the development of a legal basis to monitor the progress of mergers and acquisitions between banks through (22):

- Knowledge of the nature of the business of the Bank.

- Granting approval of the merger and acquisitions with certain institutions after studying the effect of the process on both sides ( the parent institution and the institution to be purchased)

- Determine the number of key shareholders and the rest of the shareholders

- Identify experienced managers and their ability to apply the process and follow-up

- The effect of mergers and acquisitions on a group of institutions working in the sector.

\section{Conclusion}

Paid shifts the financial and banking banks to look for new methods to correct their status, and that was through the restructuring of banking which allows the formulation of strategy and developed to meet the future challenges of financial globalization.

Restructuring the banking emerged as a result of several justifications, including increased competition in the banking industry and the emergence of banking crises as well as boiling technological developments and their role in the promotion and development of the banking business as the owner of the reorganization of the legislation and banking laws. These developments led touched by the banking industry to adopt several methods to meet the challenges of financial globalization through the convergence of banking institutions to form clusters in the field of banking in addition to the diversification of the products and services provided to customers.

Resulted in the restructuring process many benefits as a result of improved performance of the bank by controlling the cost of operations and the introduction of technology in the development of products and services offered to customers with lifting of quality to meet the challenges of competition and based on this the banks to adopt several 
strategies to be able to maintain its status within the market.

\section{References}

D . Jawdat Djafarraktab - the restructuring of banks , Empirical Study - House Tigris 2009 p 44

D. Cevdet Jafar speech - restructuring teller . Op p 553 - Dominique Thiery - Restructuration et reconversion: Concepts et méthodes. L'Harmathan Février 1995. P16

Dominique Thiery - Restructuration et reconversion Op - $p 18$

Dominique Thiery - Restructuration et reconversion op $\mathrm{p} 22$

Jennifer Goeytes \& Alionne Mobaye «Les Raisons de la restructuration du secteur bancaire en France» Université Paris1-Master1 2006-2007. Site web: www.écoparis1.ifrance.com/tpM/E42. pdf

Abdul Ghani bin Mohammed - the global financial crisis - the Sea House Publishing and Distribution / Algeria , 2008 - First Edition - 8 p.

Parrish Abdelkader - Liberation banking requirements and the development of banking services and increase the competitiveness of Algerian banks- $\mathrm{PhD}$ thesis 2005-2006 op p 44

Dhafer Saidane-la nouvelle banque-métiers et stratégies-revue banque édition 2006-PARIS

Yves Morvan- Les fondements d'économie industrielle - Edition Economica1991 p185.

Yves Morvan - Les fondements d'économie industrielle- op p 13212 - Jean Pierre ANGELEIR - Economie Industrielle: Eléments de méthodes-Edition OPU1993-p91

http://www.lefigaro.fr/sicav/2010/02/05/04006-20100205ARTFIG00546--2010-signera-le-retour-des-fusions-acquisitions-.php « 2010 signera le retourdes fusions-acquisitions »

http://www.lefigaro.fr/bourse/2010/12/31/04013-20101231ARTFIG00457-fusions-acquisitions-entre-15-et-30-de-hausse-en-2011.php

Dhafer Saidani-L'industrie bancaire-RB édition 2007

Essam El-Din Ahmed Abaza - globalization of banking - Arab Renaissance House Publishing- Cairo 2010 - 331 p.

Samir Khatib , measuring and managing risk in banks - Knowledge facility in Alexandria in $2005-85$ p.

Essam El-Din Ahmed Abaza, globalization of banking - Op 139 p. 19 - Christian de Boissieu-les systèmes financiers op p 61

Dhafer saidane-l'industrie bancaire op p 153

www.kenanonline.com/users/ahmedkourdy/topics75194 recent trends for banking services.

Look at that : - Abdul Aziz Qasim warrior - the financial crisis, causes and treatment - University House - Alexandria 2011 p 156

Hamad travel - mergers and acquisitions in the Arab countries - Halabi legal publications , Lebanon - the first edition, 2008 - p.46 